\title{
O PROJETO DO ENSINO PRIMÁRIO PARA TODOS EM MOÇAMBIQUE: 1975 A 1990
}

\section{THE PROJECT OF PRIMARY EDUCATION FOR ALL IN MOZAMBIQUE: 1975 TO 1990}

\author{
Octávio José Zimbico
}

\section{RESUMO}

O ensino primário (EP) para Todos, em Moçambique, é o foco deste texto, que problematiza o fato das taxas de admissão, escolarização, conclusão e evasão escolar no EP terem estado abaixo das expectativas entre 1975 e 1990, o que coloca a necessidade de identificar os fatores desta tendência e compreendêla, na tentativa de redução do insucesso escolar. O objetivo é compreender o comportamento dos efetivos escolares do EP, à luz da meta governamental que tinha definido a década 1980 como de erradicação do analfabetismo e "da vitória sobre o subdesenvolvimento". A metodologia consistiu na revisão bibliográfica, estudo de legislação e análise de dados estatísticos. Os principais achados mostram que fatores políticos e econômicos comprometeram esforços de universalização do EP naquele período.

Palavras-chave: Ensino primário para Todos; Moçambique; Fatores políticos e econômicos.

\begin{abstract}
Primary education (PE) for All in Mozambique is the focus of this text, which problematizes the fact that admission, schooling, completion and school dropout rates in the EP were below expectations between 1975 and 1990, what places the need of identifying the factors of this tendency and understanding it, in an attempt to reduce school failure. The aim is to understand the behavior of school personnel in the EP, in the light of the governmental goal that had defined the 1980s as eradicating illiteracy and "victory over underdevelopment." The methodology consisted of the bibliographical review, legislation study and statistical data analysis. The main findings show that political and economic factors harmed efforts to universalize PE in that period.
\end{abstract}

Keywords: Primary Education for All; Mozambique; Political and economic factors. 


\section{INTRODUÇÃO}

É supremo interesse da sociedade que em seu seio não existam homens ignorantes e faltos de educação [...] pois na ignorância e na falta de educação é que reside a fonte da miséria e da desordem, dos crimes e dos vícios de toda a sorte, como é nestes males que estão as principais causas dos perigos e desprezos sociais (OLIVEIRA, 1873, p.71).

Este trecho é do texto "O ensino público", de autoria de Antônio de Almeida Oliveira, publicado em 1873, no Maranhão, Brasil, e espelha a crença que prevalece até aos dias atuais sobre a importância do acesso ao ensino para todos em uma determinada sociedade, pois, acredita-se que combinada com políticas econômicas, a educação constitui fatorchave na promoção do bem-estar social e na redução da pobreza, ao afetar positivamente a produtividade nacional e, por via disso, determinar melhores padrões de vida. Outrossim, prevalece a crença de que a pobreza não pode ser reduzida, a menos que todas as pessoas tenham acesso a um ensino de qualidade. Com efeito, a teoria do capital humano atribui à educação o desencadeamento de processos responsáveis pela mobilidade social e modernização da sociedade. Como um sistema harmônico, a sociedade caminharia, gradual mas consistentemente, em direção ao progresso.

Um dos maiores desafios dos governos consiste em implementar políticas educativas mais justas, eficazes e relevantes. A crescente aposta no ensino de qualidade fundamenta-se na crença da contribuição do investimento em capital humano para o crescimento econômico, e outros benefícios intangíveis que a educação e a formação proporcionam aos indivíduos e à sociedade. A visão otimista do ensino, como equalizador de oportunidades para indivíduos de diferentes classes e estratos sociais, atraiu alguns teóricos da educação. Eles acreditavam que caberia à escola desfazer as desigualdades sociais, tornando-se alavanca do progresso e bem-estar; bastaria que as pessoas tivessem ânimo e talento para estudar.

Em Moçambique, o projeto de construção do socialismo iniciou-se logo após a independência, em 1975, tendo sido através dele que se pretendia edificar uma nação em que o acesso ao ensino público seria um meio pelo qual criar-se-ia iguais oportunidades de mobilidade social para todos. No entanto, apesar dos investimentos no EP, resultantes da intenção de se universalizar este nível, por um lado, as taxas de admissão, escolarização, e por outro, as de conclusão e evasão escolar parecem revelar que essa meta não foi alcançada até 1990. Essa situação coloca o desafio de identificar os fatores e mecanismos do insucesso escolar, por um lado; e de reflexões que ajudem a compreender a evolução do sistema visando a elaboração de estratégias para a redução do insucesso escolar e a melhoria da aprendizagem nas escolas, por outro.

Neste contexto, constitui objetivo deste texto, compreender o comportamento dos efetivos escolares do EP e identificar os fatores que determinaram o fluxo escolar entre 1975 e 1990, à luz do Plano Prospetivo e Indicativo, que tinha definido a década de 1980 como de erradicação do analfabetismo, através da escolarização primária universal, no âmbito dos esforços da "década de vitória sobre o subdesenvolvimento".

Com vista à obtenção de respostas ao problema formulado, este trabalho esforça-se por responder às seguintes perguntas: Qual foi o comportamento dos efetivos escolares do EP entre 1975 e 1990? Quais os fatores responsáveis pelas tendências dos efetivos escolares do EP entre 1975 e 1990? Qual foi o nível de universalização do EP até 1990 ?

A escolha do período de 1975 a 1990 justifica-se pelo fato de ter sido um momento de euforia pós-independência, em que por meio de um projeto socialista as autoridades moçambicanas queriam construir uma nação baseada na igualdade e equidade de oportunidades em todos os setores, incluindo na educação, para que através dela todos os moçambicanos tivessem a necessária inserção no projeto de construção da nação. Assim, interessanos explorar o grau de cumprimento da meta de universalização do EP no período em referência.

Em termos metodológicos, esta pesquisa é de carácter histórico e emprega diferentes dados, na busca de respostas às perguntas de investigação. A intenção é suplementar a informação, permitindo a triangulação desses dados, mediante o uso de diversas fontes na abordagem do problema de pesquisa, sob diferentes visões. As pesquisas históricas têm o mérito de ajudar a avaliar os erros e êxitos do passado, para a partir dessas experiências melhorar-se o presente e projetar-se o futuro desejado. Nesta ordem de ideias, constituem fontes de pesquisa a bibliografia, a legislação educacional e estatísticas de educação, 
recolhidos em acervos localizados na cidade de Maputo, entre 2015 e 2016.

A legislação constitui material de trabalho para pesquisadores e responsáveis pela política educativa porque oferece uma visão de ideias e valores forjados no passado, no presente, e projetados para o futuro. Por sua vez, as estatísticas de educação fornecem elementos passíveis de análise histórica, podendo ser instrumento metodológico, para classificar, quantificar, cifrar realidades.

\section{À NOVA NAÇÃO UM NOVO PROJETO EDUCACIONAL}

Proclamada a independência, em 25 de Junho de 1975, o governo de orientação socialista, sob a direção da Frente de Libertação de Moçambique (FRELIMO), único representante dos moçambicanos, lançou bases para a consolidação de um Estado dirigido por um sistema político monopartidário. As primeiras decisões do governo caracterizam a sua intenção de construir uma democracia social e política. Nesse sentido, a FRELIMO devia desmantelar o aparelho de Estado herdado, convicta que não era possível utilizar o "existente, orientando-o para novos objetivos, a partir da experiência colhida durante o governo de transição e durante os primeiros meses de independência" (GÓMEZ, 1999, p.208).

Para isso, o governo da FRELIMO desencadeou reformas, substituindo a propriedade privada da terra pela estatal, criando cooperativas agrícolas, extinguindo as profissões liberais, nacionalizando empresas, bancos, prédios, justiça, saúde, educação, entre outros serviços. A necessidade de tais reformas constava do artigo 2 da Constituição da República de 1975, em que Moçambique era um Estado de democracia popular em que todas as camadas patrióticas deviam participar na construção de uma nova sociedade, livre da exploração do homem pelo homem, em que o poder pertencesse aos operários e camponeses unidos e dirigidos pela FRELIMO e exercido pelos órgãos do poder popular (ASSEMBLEIA POPULAR DE MOÇAMBIQUE, 1975).

Todavia, mais cedo estas mudanças revelaramse ineficazes, situação agravada pela saída massiva de funcionários portugueses, que não se identificaram com o novo sistema político e pelo início da desestabilização e agressão externa dos regimes minoritários da Rodésia do Sul e do apartheid $^{1}$; tendo sido à luz destas ações que se formou a Resistência Nacional Moçambicana (RENAMO): um dos protagonistas da guerra dos 16 anos.

Para a materialização do projeto de formação do "homem novo" foram confiados os "grupos dinamizadores" "3 que, sob o centralismo democrático, deveriam difundir a linha política do partido FRELIMO. Servindo-se das experiências das zonas libertadas ${ }^{4}$ durante a guerra colonial, a educação foi posta ao serviço de "todo" o povo moçambicano. Um dos ganhos imediatos foi o alargamento do acesso à escola, o que mostrava interesse pela "democratização" do ensino. Em 1985 começa a liberalização dos principais setores da economia, partindo da reforma do Estado com vista a dotá-lo de uma visão neoliberal. Nessa altura, o discurso político dos governantes tendia a suavizar-se e a FRELIMO, em consequência das decisões do seu IV Congresso, em 1984, declarava abandono ao marxismo-leninismo e dava mais atenção ao ocidente do que aos tradicionais aliados do leste. Nesse momento,

Moçambique conheceu um turbilhão de mudanças políticas e sociais e, em 1977, a FRELIMO apresentava-se como um partido marxista-leninista de vanguarda ${ }^{5}$; em 1983, durante uma brutal guerra civil, foram introduzidos os primeiros esforços para uma abertura moçambicana e, a partir de 1989, o partido começou a evoluir no sentido da democracia neoliberal (SUMICH, 2008, p. 321).

$\mathrm{Na}$ sequência, desde 1987 Moçambique implementa um programa ${ }^{6}$ de reajustamento estrutural

\footnotetext{
${ }^{1}$ Antigo regime racista, de minoria branca, sustentado pelo Partido Nacional, que governou a República da África do Sul de 1948 a 1994

${ }^{2}$ Homem-novo era, na ótica da FRELIMO, um cidadão emancipado da dominação mental colonial, revolucionário, que servisse de modelo a replicar em escala nacional.

${ }^{3}$ Os grupos dinamizadores eram uma estrutura ideológica instalada nos bairros, em todo o país, para que servissem de difusores da linha política e idelógica da FRELIMO.

${ }^{4}$ As zonas libertadas correspondiam àqueles territórios libertados da administração colonial portuguesa durante a luta armada de libertação de Moçambique (1964 a 1974). Nessas zonas a FRELIMO ia-se instalando conforme a luta avançava.

${ }^{5}$ Foi em III congresso, em 1977, que a FRELIMO foi declarada partido marxista-leninista, tendo adotado a palavra-de-ordem "FRELIMO, partido de vanguarda da revolução socialista”.

${ }^{6}$ Moçambique foi aceito nos anos 1980 como membro do FMI e do BM. A deterioração dos termos de troca, a guerra, entre a FRELIMO e a RENAMO e calamidades naturais, levaram à aprovação, em 1987, do Programa de Reabilitação Econômica (PRE), que em 1989 integrou a componente social, tendo passado a designar-se Programa de Reabilitação Econômica e Social (PRES), através do qual liberalizou-se o mercado.
} 
e de estabilização macroeconômica, para reduzir a pobreza, com apoio do Banco Mundial (BM) e Fundo Monetário Internacional (FMI). Ditado pelas leis de mercado, este modelo econômico diminui o alcance da planificação centralizada, restringe a ingerência do Estado nos assuntos pessoais, permitindo aos cidadãos exprimir a sua iniciativa e capacidade criadora e, manifestar uma atitude independente e autônoma em relação aos problemas políticos, econômicos e sociais. Mas na elaboração da nova política educacional, a extrapolação direta dos seus mecanismos aplicáveis em setores econômicos para a educação é problemática. Esta exerce uma função específica na sociedade, por ser um direito e dever de cada cidadão. Como tal, não pode ser abandonada à iniciativa privada ou submetida absolutamente às leis do mercado, livre concorrência e busca de lucro; em suma, à lei de oferta e procura. A função fundamental de orientar a atividade educacional prestando serviços aos cidadãos cabe ao Estado, para que a concorrência não leve a situações sociais insuportáveis.

O ano de 1987, marco do início do Programa de Reabilitação Econômica (PRE), foi também de ingresso de crianças que haviam nascido em 1980.

Uma vez que a introdução das várias classes do sistema nacional de educação devia ser feita de forma progressiva [...], até 1994, altura em que se introduziria a $12^{\mathrm{a}}$ classe, haveria sempre uma classe nova a introduzir e outra do sistema antigo (TEMPO, 1987, p.17-18).

Este processo mostrava que a implementação da política educativa ainda procurava resistir aos efeitos da reestruturação do Estado moçambicano porque a introdução de um novo modelo de ensino aprovado em 1983, como importante pilar de construção de uma república socialista, era irreversível. Dessa forma, os princípios de obrigatoriedade e gratuidade do EP deviam ser garantidos tendo em vista a sua universalização para a erradicação do analfabetismo.

Em Moçambique, apesar do princípio da obrigatoriedade da instrução primária ter sido estabelecido por lei, a sua concretização se configura num exercício que não registrou avanços por não terem sido criadas condições regulamentares para sua implementação. Segundo Oliveira (1873), quatro requisitos essenciais devem preencher a lei da instrução obrigatória, o primeiro dos quais é o estabelecimento da idade escolar e a determinação do perímetro das escolas; o segundo é a atribuição ao executor de todos os meios de verificar se há meninos que deixam de aprender; o terceiro é a autorização de socorros aos pais que por sua pobreza não podem mandar os filhos à escola, como que estes sejam fornecidos de roupa e de todo o material preciso para o ensino; e o quarto é a estatuição da penalidade, em que hão-de incorrer os pais que, por culpa, deixarem de dar instrução a seus filhos. Não tendo sido criadas estas condições, ou outras idênticas, é difícil, senão impossível, implementar a escolaridade obrigatória para todos.

\section{COMPORTAMENTO DOS EFETIVOS ESCOLARES DO ENSINO PRIMÁRIO: 1975 E 1990}

Em 1976 foram criados 10 centros de formação de professores primários (CFPP), um em cada província, a fim de formar professores da $1^{\mathrm{a}}$ a $4^{\mathrm{a}}$ classe. O nível de ingresso era de $6^{\mathrm{a}}$ classe e os cursos tinham a duração de 6 meses. Os candidatos habilitados, interessados em frequentar os cursos intensivos deveriam inscreverse nas Direções Provinciais de Educação e Cultura, mediante apresentação do boletim de inscrição, de 1 a 20 de Fevereiro de cada ano, de acordo com os artigos 6 e 7 da Portaria n. ${ }^{\circ}$ 252/76, de 6 de Novembro (ASSEMBLEIA POPULAR DE MOÇAMBIQUE, 1976). Ainda nos termos desta portaria, as DPE deveriam promover a apresentação à Junta de Saúde de todos os candidatos inscritos, para a comprovação da robustez física para o exercício do ensino. Autorizada a matrícula pelo responsável político do Centro, mediante o parecer da Junta de Saúde, era fixado um prazo de 8 dias para o pagamento do valor de $200 \$$, em estampilhas fiscais a inutilizar o boletim de inscrição, no qual o candidato declarava que se comprometia a prestar serviço docente no país durante, pelo menos, três anos após a conclusão do curso.

Diferentemente do período colonial, aqui já não se faz referência à origem do aluno, pertença religiosa ou estatuto social, num sistema de ensino uno, em que as escolas passaram a ser para "todos".

Em 1979, aumentou-se a duração para um ano. Em 1983, introduz-se o modelo de $6^{\mathrm{a}}+3$ anos. Apesar das conquistas alcançadas na consolidação da formação de professores. Sobre este assunto, o Diretor Nacional de Formação de Quadros no Ministério da Educação, Miguel Lopes, abordara a sua evolução desde a altura da independência nacional, em que "contávamos 
com um número muito reduzido de quadros e alunos alfabetizados", tendo destacado os esforços realizados, que permitiram que houvesse naquele momento " $50,0 \%$ de docentes moçambicanos com formação em todos os níveis de ensino" e uma redução da total dependência da assistência internacional para a docência (TEMPO, 1986, p.8).

Dados disponíveis, sobre eficácia interna dos programas de formação de professores primários e aos crescimentos absoluto e relativo desses efetivos, revelam aumentos relativamente expressivos, que coincidem com o momento conhecido como de "explosão escolar" em Moçambique (cf. a tabela 1). Uma vez que em 1975 havia cerca de 93\% da população analfabeta, tornava-se urgente reverter esse quadro, mediante uma ampliação das oportunidades educacionais a cada vez mais moçambicanos.

Tabela 1 - Efetivos graduados das escolas de formação de professores do EP: 1976 - 1990

\begin{tabular}{|l|r|r|r|r|r|}
\hline \multirow{2}{*}{ Ano } & \multicolumn{2}{|c|}{ Professores graduados } & Total & Crescimento absoluto & Crescimento relativo \\
\cline { 2 - 4 } & CFPP (EP1) & $\mathbf{5}^{\mathbf{a}} \mathbf{e} \mathbf{6}^{\mathbf{a}}$ cl. (EP2) & & & \\
\hline 1976 & 818 & 0 & 818 & 421 & $151,5 \%$ \\
\hline 1977 & 1.239 & 0 & 1.239 & 161 & $113,0 \%$ \\
\hline 1978 & 1.400 & 0 & 1.400 & 319 & $122,8 \%$ \\
\hline 1979 & 1.594 & 125 & 1.719 & 699 & $140,7 \%$ \\
\hline 1980 & 2.318 & 100 & 2.418 & 792 & $132,8 \%$ \\
\hline 1981 & 2.959 & 251 & 3.210 & -199 & $6,2 \%$ \\
\hline 1982 & 2.868 & 143 & 3.011 & -1.079 & $35,8 \%$ \\
\hline 1983 & 1.159 & 773 & 1.932 & -1.065 & $55,1 \%$ \\
\hline 1984 & 507 & 360 & 867 & 1.045 & $220,5 \%$ \\
\hline 1985 & 1.512 & 400 & 1.912 & -520 & $27,2 \%$ \\
\hline 1986 & 1.392 & $S . I$ & 1.392 & -600 & $43,1 \%$ \\
\hline 1987 & 463 & 329 & 792 & 69 & $108,7 \%$ \\
\hline 1988 & 575 & 286 & 861 & -22 & $2,6 \%$ \\
\hline 1989 & 654 & 185 & 839 & 100 & $111,9 \%$ \\
\hline 1990 & 673 & 266 & 939 & & \\
\hline
\end{tabular}

Fonte: Estatísticas Oficiais de Educação (1990).

Essa intenção foi correspondida pelo crescente efetivo dos alunos graduados nos Centros de Formação de Professores Primários (CFPP) de 1976 a 1990, o que marca uma virada na tendência que prevaleceu durante o período anterior a 1975. Com efeito, no período posterior a 1975 , concretamente entre 1976 e 1983, o número de graduados dos CFPP aumentou continuamente. Todavia, em 1984 há uma queda acentuada do efetivo, tendência que se altera nos dois anos seguintes (1985 e 1986); sendo que entre 1987 e 1990 volta a haver outra queda. É preciso considerar os efeitos da guerra e crise econômica sobre o financiamento do SNE, de um modo geral, e dos programas de formação de professores, de modo particular. Em outra análise, constata-se que ambos os períodos são marcados por um reduzido número de professores graduados para o EP2, o que permite concluir que a pirâmide dos efetivos escolares do EP1 e EP2 tem uma base larga e um topo estreito, que corresponde à quarta parte (cerca de 25,0\%) da base, sendo este um problema histórico que dificulta a conclusão do EP com êxito.

Face à elevada taxa de analfabetismo, em 1975, foram feitas campanhas nacionais de alfabetização que visavam a conferir habilidades básicas na leitura, escrita e cálculo, com vista a integração dos moçambicanos no projeto de construção de uma nova nação. Dependendo das normas que cada país usa para avaliar os níveis de alfabetização, essas habilidades podem variar. Informações sobre as taxas de alfabetização, ainda que não sejam uma medida perfeita para a avaliação de resultados educacionais são, possivelmente, a mais vulgar, disponível e válida para comparações entre a cobertura da rede escolar e para avaliar a expansão do acesso à escola. Considerase que baixos níveis de alfabetização e educação podem impedir o desenvolvimento econômico e social de um determinado país, especialmente em 
um mundo em rápida transformação impulsionada pelo desenvolvimento científico e tecnológico. Os resultados das referidas campanhas, em termos quantitativos, podem ser vistos na tabela 2 :

Tabela 2 - Resultados das campanhas nacionais de alfabetização: 1978 - 1982

\begin{tabular}{|c|c|c|c|c|}
\hline & $\begin{array}{r}1^{\text {a }} \text { Campanha } \\
(1978 / 79) \\
\end{array}$ & $\begin{array}{r}2^{a} \text { Campanha } \\
(1980)\end{array}$ & $\begin{array}{r}3^{\text {a }} \text { Campanha } \\
(1981)\end{array}$ & $\begin{array}{r}4^{\text {a }} \text { Campanha } \\
\text { (1982) }\end{array}$ \\
\hline Matriculados (início do ano) & 300.000 & 290.000 & 246.500 & 200.364 \\
\hline Matriculados (fim do ano) & 264.067 & 253.188 & 161.193 & 82.675 \\
\hline Examinados & 315.478 & 198.579 & 117.277 & 54.984 \\
\hline Metas de Passagem & 100.000 & 200.000 & 200.000 & 200.000 \\
\hline Passagem & 139.369 & 119.394 & 61.095 & 37.430 \\
\hline
\end{tabular}

Fonte: Estatísticas Oficiais de Educação (1990).

Analisando as metas de passagem, em comparação com as de conclusão, observa-se que estas últimas estiveram sempre abaixo do estabelecido, com números inferiores à terça parte e quinta parte, na terceira e quarta campanha, respectivamente. Estes dados revelam, também, que o histórico fenômeno do insucesso escolar vinha assombrando as perspectivas das campanhas de alfabetização, de tal forma que as metas de passagem estabelecidas eram muito inferiores ao número de matriculados, ainda que o número de alfabetizandos que chegaram ao fim do ano nem sempre tenha sido muito inferior aos matriculados. As desistências são elevadas na terceira e quarta campanhas.

Como resultado dessas campanhas, e de acordo com os dados do recenseamento geral da população e habitação (de 1980), a taxa de analfabetismo reduziu de cerca de 93,0\% em 1975 para cerca de $74,0 \%$ em 1980. Com efeito, de 1978, ano em que iniciou a I campanha nacional de alfabetização, até 1983, cerca de 1,000,000 de alunos matricularam-se e cerca de 360,000 concluíram com êxito o programa (FONSECA, 1983, p.156). Nos anos seguintes, Moçambique continuou a promover a alfabetização, mas não pôde fazer mais do que se esperava devido à guerra. Assim, dos cerca de $74,0 \%$ da taxa de analfabetismo, em 1980, foi possível reduzir em cerca de $12,0 \%$ para $62,0 \%$, o que correspondia a uma população de cerca de 4.157 .000 analfabetos em 1985 (BHOLA, 1988, p.16-17).

No que se refere à escolarização da mulher jovem, era importante reduzir as "desistências de

Tabela 3 - Número de Escolas, Alunos e Professores do Ensino Primário: 1975 - 1990

\begin{tabular}{r|r|r|r|r|r|r|r|r|r|}
\hline \multirow{2}{*}{ Ano } & \multicolumn{2}{|c|}{ Escolas } & \multicolumn{2}{|c|}{ Alunos } & \multicolumn{2}{|c|}{ Professores } & \multicolumn{2}{|c|}{ Alunos/Professor } \\
\cline { 2 - 9 } & EP1 & EP2 & EP1 & EP2 & EP1 & EP2 & EP1 & EP2 \\
\hline $\mathbf{1 9 7 5}$ & 5.235 & 26 & 671.617 & 20.427 & 10.281 & S.I & 65,3 & S.I \\
\hline $\mathbf{1 9 7 6}$ & 5.853 & 88 & 1.276 .500 & 32.304 & 15.000 & S.I & 85,1 & S.I \\
\hline $\mathbf{1 9 7 7}$ & 7.076 & 94 & 1.363 .000 & 43.468 & 16.142 & 1.872 & 84,4 & 23,2 \\
\hline $\mathbf{1 9 7 8}$ & 7.104 & 88 & 1.426 .282 & 62.660 & 16.308 & 1.853 & 87,5 & 33,8 \\
\hline $\mathbf{1 9 7 9}$ & 7.170 & 96 & 1.494 .729 & 85.401 & 16.810 & 2.479 & 88,9 & 34,4 \\
\hline $\mathbf{1 9 8 0}$ & 5.730 & 99 & 1.387 .192 & 79.899 & 17.030 & 2.087 & 81,5 & 38,3 \\
\hline $\mathbf{1 9 8 1}$ & 5.709 & 99 & 1.376 .865 & 78.215 & 18.751 & 2.211 & 73,4 & 35,4 \\
\hline $\mathbf{1 9 8 2}$ & 5.722 & 111 & 1.333 .050 & 80.746 & 20.584 & 2.361 & 64,8 & 34,2 \\
\hline $\mathbf{1 9 8 3}$ & 5.886 & 128 & 1.220 .139 & 91.044 & 20.769 & 1.751 & 58,7 & 52,0 \\
\hline $\mathbf{1 9 8 4}$ & 4.990 & 137 & 1.303 .650 & 103.970 & 21.903 & 2.290 & 59,5 & 45,4 \\
\hline $\mathbf{1 9 8 5}$ & 4.616 & 156 & 1.311 .014 & 111.283 & 20.286 & 2.411 & 64,6 & 46,2 \\
\hline $\mathbf{1 9 8 6}$ & 4.430 & 161 & 1.305 .582 & 113.948 & 20.756 & 2.446 & 62,9 & 46,6 \\
\hline $\mathbf{1 9 8 7}$ & 3.927 & 154 & 1.286 .961 & 75.877 & 20.884 & 2.161 & 61,6 & 35,1 \\
\hline $\mathbf{1 9 8 8}$ & 3.647 & 163 & 1.199 .669 & 78.380 & 21.410 & 2.452 & 56,0 & 32,0 \\
\hline $\mathbf{1 9 8 9}$ & 3.496 & 168 & 1.210 .671 & 96.907 & 21.039 & 2.377 & 57,5 & 40,8 \\
\hline $\mathbf{1 9 9 0}$ & 3.441 & 169 & 1.260 .218 & 116.718 & 23.107 & S.I & 54,5 & S.I \\
\hline
\end{tabular}

Fonte: Estatísticas Oficiais de Educação (2003). 
meninas no EP e permitir o seu ingresso nos diversos cursos técnico-profissionais. O Ministério da Educação deveria divulgar os cursos em que a mulher já tivesse revelado aptidões especiais e favorecer o seu acesso" (TEMPO, 1984, p.22).

De acordo com a tabela 3 , o número de professores, no EP1 e EP2, registra um crescimento entre 1975 e 1990. Contrariamente a essa tendência, o número de escolas depois de crescer entre 1975 a 1979, devido aos efeitos destrutivos da guerra foi decrescendo, até que em 1990 chegou a situar-se abaixo da metade da capacidade instalada em 1983, não tendo o número de alunos aumentado significativamente. A relação professor/alunos continuava elevada até 1989, ainda que o efetivo de professores fosse cada vez mais elevado, quer no EP1 $(57,5)$ assim como no EP2 $(40,8)$. Estas condições degradam o ambiente das aulas porque, geralmente, os professores têm dificuldades de assistir a um número de alunos relativamente elevado por classe. Outrossim, independentemente da redução drástica do número de escolas na década de 1980, o efetivo escolar continuou crescendo, o que contribuiu para a acentuação da relação alunos/ professor. Merece destaque que o número de alunos do EP2 desde 1975 tenha sido tantas vezes inferior ao dos do EP1, o que em termos práticos significou que a maioria dos alunos que ingressavam no EP1 não concluíam o EP de 7 classes, aumentando as possibilidades de um efetivo de pessoas que não desenvolviam habilidades de leitura, escrita e cálculo. Estes dados demonstram, também, que adicionando o número de alunos que não concluem o EP ao dos que não têm acesso à escola, a escolarização básica universal ainda estava muito longe de ser alcançada; e nestes moldes, não se vislumbrava, pelo menos a curto ou médio prazos, qualquer possibilidade de escolarização básica universal em Moçambique, sobretudo atendendo ao crescimento médio anual da população e do efetivo escolarizável.

Segundo Mário et al. (2002), tendo em vista a melhoria da qualidade de ensino, o Sistema Nacional de Educação (SNE) foi submetido a uma avaliação diagnóstica de todas as suas componentes, com o objetivo de rever profundamente os seus objetivos, estrutura e funcionamento e desenvolver estratégias de ensino-aprendizagem que o tornassem mais efetivo. Mário et al. (2002), citam exemplos dos seminários nacionais de língua portuguesa e matemática
(1979-1980), cujas recomendações indicavam a necessidade de recrutamento de professores das escolas primárias, secundárias e terciárias, bem como especialistas internacionais que ajudassem a planificar o SNE. Adicionalmente, tal revisão tinha o objetivo de adaptar o sistema de educação às demandas do I Plano Nacional de Desenvolvimento. Com o fim da guerra no Zimbábue, em 1979, e com a expectativa da paz na região Austral de África, o governo moçambicano formulou o Plano Prospetivo Indicativo que orientava a reestruturação da economia com o objetivo de estabelecer independência e equilíbrio econômico entre as províncias.

O SNE aprovado pelo parlamento em 1982 seguiu-se a um debate público, enfatizando-se o direito à educação e a erradicação do analfabetismo e da pobreza, bem como a introdução da escolaridade obrigatória e universal para crianças que completassem 7 anos de idade. Dada a relevância e prioridade, a formação de professores e a alfabetização foram estruturados como subsistemas, de acordo com as necessidades do país definidas pelo Plano Prospectivo Indicativo (PPI). Uma primeira análise do currículo do EP foi feita entre 1983 e 1986, tendo-se chegado à conclusão de que muitos problemas tinham surgido entre 1979 e 1980, particularmente relacionados ao ensino da língua portuguesa. Com efeito, o Instituto Nacional do Desenvolvimento da Educação (INDE) tinha concluído que "a metodologia de ensino da língua portuguesa como língua segunda não promovia a aprendizagem das crianças, em todo o ambiente social onde a língua portuguesa não era usada", fato que levava a elevadas taxas de reprovação, sobretudo em classes iniciais. Por exemplo, "em 1986, a taxa média de reprovação no $\mathrm{EP}$, em escala nacional, foi de 40\%" (MÁRIO et al., 2002, p.6). Na tabela que se segue apresentamos os indicadores de cobertura da rede escolar primária. 
Tabela 4 - Indicadores de cobertura da rede escolar do Ensino Primário em Moçambique: 1975 - 1990

\begin{tabular}{|r|r|r|r|r|r|r|r|r|r|r|}
\hline Ano & $\begin{array}{r}\text { Pop. dos 7 } \\
\text { a 13 anos }\end{array}$ & $\begin{array}{r}\text { Alunos } \\
\text { (EP1+EP2) }\end{array}$ & $\begin{array}{r}\text { Taxa } \\
\text { bruta } \\
\text { escolariz. }\end{array}$ & $\begin{array}{r}\text { Alunos dos } \\
\text { 7 a 13 anos }\end{array}$ & $\begin{array}{r}\text { Taxa } \\
\text { líquida de } \\
\text { escolariz. }\end{array}$ & $\begin{array}{r}\text { População } \\
\text { de 7 anos }\end{array}$ & $\begin{array}{r}\text { Alunos de 7 } \\
\text { anos na 1a } \mathbf{~ c l . ~}\end{array}$ & $\begin{array}{r}\text { Taxa adm. } \\
\text { id.esp }\end{array}$ & $\begin{array}{r}\text { Alunos 1 } \\
\text { classe }\end{array}$ & $\begin{array}{r}\text { Taxa } \\
\text { bruta ad. }\end{array}$ \\
\hline $\mathbf{1 9 7 5}$ & 1.831 .541 & 692.044 & $37,8 \%$ & 338.716 & $48,9 \%$ & 295.636 & 131.853 & $44,6 \%$ & 130.008 & $38,4 \%$ \\
\hline $\mathbf{1 9 7 6}$ & 1.876 .579 & 1.308 .804 & $69,7 \%$ & 347.046 & $26,5 \%$ & 302.906 & 135.667 & $44,8 \%$ & 135.908 & $39,2 \%$ \\
\hline $\mathbf{1 9 7 7}$ & 1.922 .724 & 1.406 .468 & $73,1 \%$ & 355.579 & $25,3 \%$ & 310.355 & 132.312 & $42,6 \%$ & 142.786 & $40,2 \%$ \\
\hline $\mathbf{1 9 7 8}$ & 1.970 .004 & 1.488 .942 & $75,6 \%$ & 364.323 & $24,5 \%$ & 317.986 & 130.458 & $41,0 \%$ & 155.654 & $42,7 \%$ \\
\hline $\mathbf{1 9 7 9}$ & 2.018 .447 & 1.580 .130 & $78,3 \%$ & 373.282 & $23,6 \%$ & 325.806 & 127.551 & $39,1 \%$ & 160.331 & $43,0 \%$ \\
\hline $\mathbf{1 9 8 0}$ & 2.068 .081 & 1.467 .091 & $70,9 \%$ & 382.461 & $26,1 \%$ & 333.817 & 165.001 & $49,4 \%$ & 158.980 & $41,6 \%$ \\
\hline $\mathbf{1 9 8 1}$ & 2.118 .935 & 1.455 .080 & $68,7 \%$ & 391.866 & $26,9 \%$ & 342.026 & 145.006 & $42,4 \%$ & 153.455 & $39,2 \%$ \\
\hline $\mathbf{1 9 8 2}$ & 2.171 .040 & 1.413 .796 & $65,1 \%$ & 401.502 & $28,4 \%$ & 350.436 & 133.225 & $38,0 \%$ & 146.552 & $36,5 \%$ \\
\hline $\mathbf{1 9 8 3}$ & 2.224 .427 & 1.311 .183 & $58,9 \%$ & 411.375 & $31,4 \%$ & 359.054 & 130.889 & $36,5 \%$ & 137.654 & $33,5 \%$ \\
\hline $\mathbf{1 9 8 4}$ & 2.279 .126 & 1.407 .620 & $61,8 \%$ & 421.491 & $29,9 \%$ & 367.883 & 134.107 & $36,5 \%$ & 134.556 & $31,9 \%$ \\
\hline $\mathbf{1 9 8 5}$ & 2.335 .170 & 1.422 .297 & $60,9 \%$ & 431.855 & $30,4 \%$ & 376.929 & 137.405 & $36,5 \%$ & 128.012 & $29,6 \%$ \\
\hline $\mathbf{1 9 8 6}$ & 2.392 .592 & 1.419 .530 & $59,3 \%$ & 442.475 & $31,2 \%$ & 386.198 & 140.784 & $36,5 \%$ & 133.465 & $30,2 \%$ \\
\hline $\mathbf{1 9 8 7}$ & 2.451 .426 & 1.362 .838 & $55,6 \%$ & 453.355 & $33,3 \%$ & 395.695 & 144.246 & $36,5 \%$ & 137.331 & $30,3 \%$ \\
\hline $\mathbf{1 9 8 8}$ & 2.511 .707 & 1.278 .049 & $50,9 \%$ & 464.503 & $36,3 \%$ & 405.425 & 147.793 & $36,5 \%$ & 129.005 & $27,8 \%$ \\
\hline $\mathbf{1 9 8 9}$ & 2.573 .470 & 1.307 .578 & $50,8 \%$ & 475.925 & $36,4 \%$ & 415.394 & 151.427 & $36,5 \%$ & 130.709 & $27,5 \%$ \\
\hline $\mathbf{1 9 9 0}$ & 2.636 .752 & 1.376 .936 & $52,2 \%$ & 487.628 & $35,4 \%$ & 425.609 & 155.151 & $36,5 \%$ & 145.567 & $29,9 \%$ \\
\hline
\end{tabular}

Legenda:

- Taxa bruta de escolarização: quociente entre o número total de alunos num ciclo e a população do grupo de idade correspondente ao ciclo.

- Taxa líquida de escolarização: quociente entre o número de alunos de idade escolar correspondente a um ciclo e a população de idade escolar correspondente a este ciclo.

- Taxa de admissão por idade específica: quociente entre o número de alunos de idade específica no $1^{\circ}$ ano de estudo e a população da mesma idade específica.

- Taxa bruta de admissão: quociente entre o número de alunos no $1^{\circ}$ ano de estudo e a população de idade oficial de admissão.

Fonte: Produzido pelo autor, a partir das estatísticas oficiais de educação (2003).

De acordo com a tabela 4, as taxas brutas de admissão, entre 1975 e 1990, variam de cerca de 27,5 a $43,0 \%$ da população com idade oficial de admissão, que era de 7 anos, nos termos da Lei n. ${ }^{\circ}$ 4/83, de 23 de Março (ASSEMBLEIA POPULAR DE MOÇAMBIQUE, 1983). Outrossim, a taxa de escolarização por idade específica mostra crescimentos entre os cerca de 23,6 a 48,9\%, em igual período, o que em termos práticos significa que menos de metade das crianças matricularam no primeiro ano de escolaridade com a idade específica (de 7 anos). A implicação disso é que mais de metade das crianças inicie o EP com mais de 6 anos de idade. Por sua vez, a taxa bruta de admissão, no referido período (que varia de cerca de 27,5 a 43,0\%), mostra uma tendência crescente. Significa que o número de alunos matriculados no primeiro ano de escolaridade é, também, de cerca de um terço a quase metade da população moçambicana com 6 anos de idade.
A taxa bruta de escolarização, ainda no mesmo período, revela uma variação dos cerca de 37,8 a $78,3 \%$, o que significa que do efetivo total escolarizável (população dos 6 aos 12 anos), nem todas as crianças em idade escolar conseguem ter acesso à escola no devido tempo, sendo que outras tantas não conseguem definitivamente. Por sua vez, a taxa líquida de escolarização variou de cerca de 23,6 a 48,9\% entre 1975 e 1990, mas com uma acentuada queda nos anos 1976 a 1981; o que significa que do total de alunos que frequentam o Ensino Primário, pouco mais de um terço, e menos de metade, está na idade oficial de frequência do EP (dos 6 aos 12 anos). A implicação lógica desta tendência é que mais de metade dos alunos frequenta o EP fora da idade oficialmente estabelecida para o efeito. Concretamente, tal significa que o EP não tem conseguido satisfazer a demanda do ponto de vista da observância das etapas de desenvolvimento físico e mental das crianças, ao longo das classes. 


\section{FATORES QUE INFLUENCIARAM A CONFIGURAÇÃO DO ENSINO PRIMÁRIO: 1975 A 1990}

A introdução, em 1987, do PRE, implicava alterações no funcionamento do aparelho estatal. Das mudanças de particular impacto na educação ressaltam-se os consideráveis cortes no gasto público, que num contexto em que grandes verbas acabavam por ser destinadas aos esforços de guerra, redundaram em cortes em setores essenciais. "Se no período 1980 1986 o setor da educação respondia por 17 a 19,0\% dos gastos correntes do governo, tal percentagem foi reduzida para 9,0\% em 1987" (GÓMEZ, 1999, p.14).

Algumas medidas de melhoria do rendimento escolar já tinham começado a ser tomadas. Com efeito, em princípios de 1985, as escolas da capital do país assinaram compromissos de rendimento escolar, até porque o aumento dos níveis "de rendimento escolar dos alunos e a elevação do nível de ensino eram os principais objetivos a que se comprometiam alcançar as instituições de ensino" (TEMPO, 1985, p.4).

Em Março de 1988, eram relatados casos de mais de doze mil crianças não teriam acesso à escola, na Cidade de Maputo. Enquanto isso, "verificavase uma burocracia na venda do material escolar ou mesmo a sua chegada tardia às diversas escolas do país" (TEMPO, 1988, p.9). A crise agudizava-se. Com a falta de escolas no país, o Ministro da Educação tinha adotado um regulamento que visava dar prioridade às crianças mais novas, porque no ano de 1988 tinha havido muitos casos de crianças com idades dos 14 e 17 anos que haviam passado para a $5^{\mathrm{a}}$ e $6^{\mathrm{a}}$ classes, mas que não se haviam matriculado nas escolas por serem consideradas crescidas, para além das que tinham reprovado duas vezes nas mesmas classes. Nestas circunstâncias, e nos termos do referido regulamento, tais crianças deviam ficar dois anos em casa sem estudar.

O número de escolas, no país, em 1989, tinha baixado de forma acentuada, sobretudo nos subsistemas de ensino geral e de educação de adultos. No caso do EP1, de 5,886 escolas existentes em 1983 passaram para cerca de 3,500 no fim de 1988. "A rede escolar tinha diminuído em cerca de 2,400 escolas, na sua quase totalidade situada nas zonas rurais" (TEMPO, 1989, p.22).

Em termos de distribuição territorial dos danos, as províncias mais afetadas foram: Zambézia, Nampula, Inhambane e Gaza. Ao nível do EP1, a rede escolar encerrada ou destruída situou-se em cerca de metade, ao passo que no EP2 o número de escolas destruídas ou encerradas foi de apenas 18\% (quinta parte do total). É preciso prestar atenção ao fato de o número de escolas do EP2 ser muito inferior ao das do EP1. Mais detalhes podem ser vistos na tabela 5 sobre o impacto da guerra na rede escolar primária.

Tabela 5 - Impacto da guerra sobre a rede escolar primária em Moçambique: 1983 - 1992

\begin{tabular}{|c|c|c|c|c|c|c|c|c|c|c|}
\hline \multirow{4}{*}{ Província } & \multicolumn{5}{|c|}{ Ensino Primário do I Grau (EP1) } & \multicolumn{5}{|c|}{ Ensino Primário do II Grau (EP2) } \\
\hline & \multicolumn{3}{|c|}{ Escolas } & \multicolumn{2}{|c|}{ Afetados } & \multicolumn{3}{|c|}{ Escolas } & \multicolumn{2}{|c|}{ Afetados } \\
\hline & \multirow[t]{2}{*}{$\begin{array}{l}\text { Existente } \\
\text { em } 1983\end{array}$} & \multicolumn{2}{|c|}{$\begin{array}{c}\text { Encerradas e } \\
\text { destruídas }\end{array}$} & \multirow[t]{2}{*}{ Alunos } & \multirow[t]{2}{*}{ Prof. } & \multirow[t]{2}{*}{$\begin{array}{r}\text { Existente } \\
\text { em } 1983\end{array}$} & \multicolumn{2}{|c|}{$\begin{array}{l}\text { Encerradas } \\
\text { e destruídas }\end{array}$} & \multirow[t]{2}{*}{ Alunos } & \multirow[t]{2}{*}{ Prof. } \\
\hline & & $\mathbf{N}^{0}$ & $\%$ & & & & $\mathbf{N}^{\mathbf{0}}$ & $\%$ & & \\
\hline Niassa & 508 & 361 & $71,1 \%$ & 53.927 & 1.278 & 17 & 10 & $58,8 \%$ & 1.517 & 79 \\
\hline Cabo Delgado & 542 & 160 & $29,5 \%$ & 94.375 & 1.944 & 12 & 0 & $0,0 \%$ & 104 & 6 \\
\hline Nampula & 1.116 & 553 & $49,6 \%$ & 255.650 & 3.051 & 32 & 0 & $0,0 \%$ & 0 & 0 \\
\hline Zambézia & 1.130 & 997 & $88,2 \%$ & 286.264 & 5.330 & 27 & 8 & $29,6 \%$ & 3.451 & 70 \\
\hline Tete & 479 & 454 & $94,8 \%$ & 98.923 & 1.278 & 9 & 4 & $44,4 \%$ & 2.342 & 56 \\
\hline Manica & 225 & 109 & $48,4 \%$ & 31.569 & 595 & 10 & 0 & $0,0 \%$ & 0 & 0 \\
\hline Sofala & 386 & 254 & $65,8 \%$ & 68.429 & 925 & 14 & 8 & $57,1 \%$ & 2.848 & 52 \\
\hline Inhambane & 506 & 223 & $44,1 \%$ & 179.237 & 2.681 & 12 & 0 & $0,0 \%$ & 507 & 22 \\
\hline Gaza & 546 & 183 & $33,5 \%$ & 197.236 & 3.240 & 19 & 0 & $0,0 \%$ & 0 & 0 \\
\hline $\begin{array}{l}\text { Maputo Provín- } \\
\text { cia }\end{array}$ & 339 & 204 & $60,2 \%$ & 47.288 & 828 & 9 & 2 & $22,2 \%$ & 1.382 & 261 \\
\hline Maputo Cidade & 109 & 0 & $0,0 \%$ & 101.324 & 1.311 & 15 & 0 & $0,0 \%$ & 1.115 & 15 \\
\hline Total & 5.886 & 3.498 & $59.4 \%$ & 1.414 .222 & 22.461 & 176 & 32 & $18,0 \%$ & 13.266 & 561 \\
\hline
\end{tabular}

Fonte: Estatísticas oficiais de Educação (1992). 
A "década de 1980 começou mal e terminou melhor. Agora há um pouco de tudo no mercado, só falta dinheiro. Antes ter para ver apenas, do que não haver nada. O governo deve-se aplicar mais na resolução da guerra. Já ninguém aguenta com esta guerra" - dizia Issufo Omar, cidadão entrevistado pela Tempo na passagem do ano de 1989 para 1990, no bairro da Mafalala, em Maputo. Issufo mostrava-se sensível às reformas políticas do leste da Europa e prosseguia:

É uma etapa histórica bastante interessante e nós, moçambicanos, temos de tirar alguns ensinamentos do fenômeno que se está a dar na Europa. Se eles mudam, nós não vamos manter a mesma posição. É altura, agora, de o partido FRELIMO se abrir mais na sua política, porque de contrário poderá ficar ultrapassado (TEMPO, 1990, p.13).

Issufo Omar defendia que fossem criados mais partidos políticos em Moçambique para que as "eleições tivessem realmente sentido" (TEMPO, 1990, 14). Nesse momento, o anteprojeto de revisão da Constituição da República estava em debate, e "pela sua importância e atualidade, dado tratar-se de um documento que se destinava a ser discutido por todos os cidadãos moçambicanos" (TEMPO, 1990, p.25).

No início do ano letivo de 1990, as estatísticas mostravam que muitas crianças não tinham acesso à escola. Na sua maioria eram vítimas de guerra e seu futuro era considerado incerto:

A exiguidade da rede escolar é reflexo direto da guerra. Escolas em número de 2.655 em todo o país foram destruídas ou encerradas, o que representa $45,0 \%$ do total. Nas províncias de Tete e Zambézia, os efeitos da guerra atingiram perto de $80,0 \%$ da destruição da rede escolar, enquanto nas províncias de Sofala, Niassa e Maputo-província ronda os 50,0\%. Num cálculo imediato tinham-se apurado cerca de 500.000 crianças sem a possibilidade de continuar os estudos. Mas porque a resposta ao fenômeno ainda estava por se dar, o número estava progressivamente a subir. 1.800 .000 crianças dos 7 aos 11 anos corriam o risco de não estudar naquele ano (TEMPO, 1990, p.24).

Uma análise mais global, tinha constatado que cerca de 3.000.000 de crianças em idade escolar sofriam, direta ou indiretamente, os efeitos da guerra. Deste modo, o efetivo docente necessário para suprir essas necessidades era de 20.000 professores, mas naquele momento só era possível capacitar cerca de 9.000 professores.
Tendo em vista uma resposta concertada para o problema, uma ação multissetorial estava na forja. O Departamento de Educação Especial, o Ministério da Saúde e as Organizações Democráticas de Massas eram chamados a encontrar alternativas de reabilitação das crianças vítimas de guerra. No entanto, um problema se colocava: os programas elaborados só podiam alcançar cerca de 1.200 .000 crianças dos 7 aos 11 anos. Logo, que destino seria dado às restantes cerca de 1.800.000?

A resposta a esta pergunta talvez se eventasse que se encontrasse nas Diretivas Econômicas e Sociais do V Congresso do Partido FRELIMO que preconizavam a intervenção organizada da comunidade. Tal envolvimento comunitário implicaria a construção de escolas que não serviriam apenas os utentes por cuja iniciativa tivessem sido criadas, mas destinar-se-iam, também, a servir à comunidade no raio da ação em que estivessem inseridas e não pressupusessem a obtenção de lucros (TEMPO, 1990, p.24).

Nesse momento, decorridas 7 semanas após o V Congresso da FRELIMO, ainda não havia sido aprovada uma legislação que regulamentasse as atividades das escolas comunitárias, privadas tampouco a ação dos explicadores em Moçambique. Não obstante, a privatização de várias atividades era a palavra de ordem.

No geral, o ano de 1990 acabou sendo dos mais complicados. As aulas começaram com um mês de atraso e os resultados, em muitos casos, não correspondiam ao rendimento escolar dos alunos: "houve fraude de toda ordem, no que teve saliência a venda de notas" (TEMPO, 1990, p.7). No referido momento, também, havia reivindicação de melhores condições de trabalho, aumentos salariais e integração na carreira docente. Os professores a desencadeavam "as greves de direito", com impacto no funcionamento das escolas:

O ano letivo de 1990 já estava em curso, mas as três semanas de atraso no seu início começava a preocupar as direções das escolas que teriam de se embrenhar em "ginásticas" para cumprir os programas de ensino. Os professores haviam regressado às escolas "pelas crianças", mas descontentes, e continuavam à espera que o Governo encontrasse soluções para os problemas que os levara a empreender uma greve de 15 dias (TEMPO, 1990, p.3). 
A fraude e as exigências por melhores condições de trabalho e incrementos salariais eram fenômenos novos na história de Moçambique. Aparentemente duas razões justificam este cenário: por um lado, a degradação das condições de trabalho devido à crise econômica; por outro, o sentimento de relativa liberdade nas reivindicações dos direitos trabalhistas, em particular, e de toda a população, no geral, em resultado da abertura política que se seguiu à reforma do Estado desde o início da virada política e econômica.

Como resultado da combinação de fatores políticos e econômicos, a seguir discutimos a eficácia interna do Ensino Primário, em forma de taxas de conclusão. Como se pode ver, as taxas de conclusão, no EP1 e no EP2, eram baixas, o que representava baixo rendimento e enorme desperdício escolar,

Tabela 6 - Taxas de conclusão no Ensino Primário: 1975 - 1990

\begin{tabular}{|r|r|r|r|r|r|r|r|r|}
\hline \multirow{2}{*}{ Ano } & \multicolumn{2}{|c|}{ Alunos } & \multicolumn{2}{|c|}{ Graduados } & \multicolumn{2}{c|}{ Percentagem } & \multicolumn{2}{|c|}{ Diferença } \\
\cline { 2 - 10 } & $\mathbf{E P 1}$ & $\mathbf{E P 2}$ & $\mathbf{E P 1}$ & $\mathbf{E P 2}$ & $\mathbf{E P 1}$ & $\mathbf{E P 2}$ & $\mathbf{E P 1}$ & EP2 \\
\hline $\mathbf{1 9 7 5}$ & 671.617 & 20.427 & 19.660 & 3.600 & $2,9 \%$ & $17,6 \%$ & $97,1 \%$ & $82,4 \%$ \\
\hline $\mathbf{1 9 7 6}$ & 1.276 .500 & 32.304 & 25.269 & 5.920 & $2,0 \%$ & $18,3 \%$ & $98,0 \%$ & $81,7 \%$ \\
\hline $\mathbf{1 9 7 7}$ & 1.363 .000 & 43.468 & 39.536 & 10.191 & $2,9 \%$ & $23,4 \%$ & $97,1 \%$ & $76,6 \%$ \\
\hline $\mathbf{1 9 7 8}$ & 1.426 .282 & 62.660 & 62.774 & 9.899 & $4,4 \%$ & $15,8 \%$ & $95,6 \%$ & $84,2 \%$ \\
\hline $\mathbf{1 9 7 9}$ & 1.494 .729 & 85.401 & 74.029 & 12.270 & $5,0 \%$ & $14,4 \%$ & $95,0 \%$ & $85,6 \%$ \\
\hline $\mathbf{1 9 8 0}$ & 1.387 .192 & 79.899 & 82.689 & 18.182 & $6,0 \%$ & $22,8 \%$ & $94,0 \%$ & $77,2 \%$ \\
\hline $\mathbf{1 9 8 1}$ & 1.376 .865 & 78.215 & 83.393 & 16.111 & $6,1 \%$ & $20,6 \%$ & $93,9 \%$ & $79,4 \%$ \\
\hline $\mathbf{1 9 8 2}$ & 1.333 .050 & 80.746 & 58.814 & 14.169 & $4,4 \%$ & $17,5 \%$ & $95,6 \%$ & $82,5 \%$ \\
\hline $\mathbf{1 9 8 3}$ & 1.220 .139 & 91.044 & 65.225 & 14.329 & $5,3 \%$ & $15,7 \%$ & $94,7 \%$ & $84,3 \%$ \\
\hline $\mathbf{1 9 8 4}$ & 1.303 .650 & 103.970 & 72.743 & 20.176 & $5,6 \%$ & $19,4 \%$ & $94,4 \%$ & $80,6 \%$ \\
\hline $\mathbf{1 9 8 5}$ & 1.311 .014 & 111.283 & 75.204 & 14.949 & $5,7 \%$ & $13,4 \%$ & $94,3 \%$ & $86,6 \%$ \\
\hline $\mathbf{1 9 8 6}$ & 1.305 .582 & 113.948 & $\mathrm{~S} . \mathrm{I}$ & 17.115 & $\mathrm{~S} . \mathrm{I}$ & $15,0 \%$ & $\mathrm{~S} . \mathrm{I}$ & $85,0 \%$ \\
\hline $\mathbf{1 9 8 7}$ & 1.286 .961 & 75.877 & 63.433 & 18.677 & $4,9 \%$ & $24,6 \%$ & $95,1 \%$ & $75,4 \%$ \\
\hline $\mathbf{1 9 8 8}$ & 1.199 .669 & 78.380 & 71.845 & 12.952 & $6,0 \%$ & $16,5 \%$ & $94,0 \%$ & $83,5 \%$ \\
\hline $\mathbf{1 9 8 9}$ & 1.210 .671 & 96.907 & 77.771 & 10.715 & $6,4 \%$ & $11,1 \%$ & $93,6 \%$ & $88,9 \%$ \\
\hline $\mathbf{1 9 9 0}$ & 1.260 .218 & 116.718 & 79.622 & 16.871 & $6,3 \%$ & $14,5 \%$ & $93,7 \%$ & $85,5 \%$ \\
\hline
\end{tabular}

Fonte: Estatísticas Oficiais de Educação (2003).

desafiava a quantidade e qualidade de recursos educacionais, problemas cuja solução carecia de políticas inovadoras.

Os dados da tabela 6 revelam que ao nível do EP1 (em 1975) a percentagem de graduados foi de 2,9\%, ao passo que no EP2 foi de $17,6 \%$, valores cujas diferenças calculadas à base dos $100 \%$ revelam um enorme desperdício escolar, na ordem dos 97,1\% e $82,4 \%$, respetivamente. Em termos globais, estes dados significam que apenas cerca de $10,0 \%$ dos alunos que estavam matriculados no EP conseguiam concluir o nível. Esta tendência prevaleceu até 1990.

Uma observação das taxas de diferença entre a percentagem de graduados face aos alunos matriculados, tanto no EP1 como no EP2, pode levar à falsa impressão de que essa diferença representa, na sua totalidade, o desperdício escolar. Não necessariamente! Embora nela esteja inclusa a quantidade dos que não concluíram o EP1 e o EP2 dentro do tempo previsto. Destas largas percentagens fazem parte, também, os alunos que estavam a frequentar o Ensino Primário, em classes de transição, como sejam os casos dos alunos da $2^{\mathrm{a}}, 3^{\mathrm{a}}, 4^{\mathrm{a}}$ e $6^{\mathrm{a}}$ classe.

\section{CONSIDERAÇÕES FINAIS}

Ainda que seja dever da família instruir o filho e do Estado promover e facilitar o cumprimento do dever 
do pai, devendo para isso o Estado abrir escolas, em toda a parte, e esperar que as façam frequentar por seus filhos todos aqueles pais, que não puderem educá-los particularmente, como sublinha Oliveira (1873, p.71), em Moçambique, as condições concretas de oferta do ensino comprometeram o projeto de universalização do acesso à escola primária entre 1975 e 1990. Se de 1975 a 1979 houve uma explosão escolar caracterizada por um expressivo aumento do número de alunos e professores, mais cedo essa tendência mudou, sobretudo a partir de 1983 com o recrudescimento da guerra, crise econômica e calamidades naturais, o que certamente acabou por afetar negativamente a "vitória sobre o subdesenvolvimento" nos anos 1980.

Constituiu um destacado evento político a guerra (que destruiu mais de metade da rede escolar instalada até 1983, sobretudo no meio rural, onde se localizava a maioria da população). Outro fator adverso foi a saída massiva de profissionais considerados qualificados, que não se identificaram com o novo regime, logo após a independência (em 1975). A transposição da experiência educativa das zonas libertadas para um contexto diferente, como mostra Gómez (1999), fez com que o governo moçambicano não fosse capaz de estimar as reais necessidades da nova nação, o que resultou numa definição de metas extremamente ambiciosas e defa3usadas das condições humanas, materiais e contextuais daquele momento. Em termos de abordagem das políticas educativas, a ausência da regulamentação da escolaridade obrigatória e gratuita pelo conselho de ministros - tal como estabelecia a Lei n. ${ }^{\circ} 4 / 83$, de 23 de Março - omitiu as responsabilidades das famílias e do Estado no cumprimento do contrato social de oferta de um ensino primário obrigatório e gratuito para todos.

Em termos econômicos, a crise (exacerbada pela guerra e cíclicas calamidades naturais) também foi determinante para a fraca expansão e cobertura da rede escolar primária. Outro importante fator foi o colapso econômico do bloco socialista, que vinha apoiando Moçambique desde a luta de libertação nacional, o que obrigou o país a procurar novas parcerias econômicas, tendo, por conseguinte, sido obrigado a proceder a reajustamentos nas suas políticas econômicas e sociais como condição para o estabelecimento da ajuda financeira, que seria a base para a normalização do funcionamento de diversos serviços sociais, incluindo a educação. Tais reajustamentos incluíam a redução do orçamento do Estado e do efetivo de profissionais em diversas áreas, o que por sua vez afetou a capacidade de formação e colocação de um número de professores que procurasse satisfazer as necessidades, decorrentes do crescimento da população escolarizável e do êxodo rural impulsionado pela guerra.

As taxas de admissão e de escolarização, por um lado, mostram que nem todas as crianças conseguiam ter acesso a escola, por outro, revelam que outras tantas ingressavam para além da idade oficialmente estabelecida. Ligados a este fenômeno estariam outros que influenciam diretamente o acesso à escola tais como a disponibilidade de estabelecimentos escolares, material escolar, condição socioeconômica das famílias e do país, de um modo geral. Em suma, o acesso à escola primária entre 1975 e 1980, muitas vezes se situou abaixo do efetivo populacional escolarizável.

Em termos de eficácia interna, as taxas de conclusão também se situavam pouco abaixo da metade do esperado, principalmente ao nível do EP1 onde as dificuldades de iniciação à leitura e escrita têm sido notáveis. Como diriam Mário et al. (2002), as avaliações feitas ao ensino primário na década de 1980 tinham revelado que muitos destes problemas surgiram em momento da subida vertiginosa dos efetivos escolares, em parte, graças à euforia pósindependência e às massivas campanhas nacionais de alfabetização, tendo em vista a reversão da taxa de analfabetismo de 93,0\%, mal-grado esse crescimento não ter sido acompanhado pela devida capacidade instalada para o normal funcionamento das escolas, o que certamente degradou a qualidade do ensino primário.

\section{REFERÊNCIAS BIBLIOGRÁFICAS}

ASSEMBLEIA POPULAR DE MOÇAMBIQUE. Constituição da República Popular de Moçambique. Maputo: Imprensa Nacional de Moçambique, 1975.

ASSEMBLEIA POPULAR DE MOÇAMBIQUE. Lei $\mathbf{4 / 8 3}$, de 23 de Março: aprova a lei do Sistema Nacional de Educação e define os princípios fundamentais na sua aplicação. Maputo: Imprensa Nacional de Moçambique, 1983.

ASSEMBLEIA POPULAR DE MOÇAMBIQUE. Portaria n. ${ }^{\circ}$ 252/76, de 6 de Novembro: institui, ao nível das províncias, Centros de Formação de Professores Primários. Maputo: Imprensa Nacional de Moçambique, 1976. 
BHOLA, H. S. Literacy for Revitalization in the SADCC countries of Southern Africa (Paper presented at the Modern Language Association Right to Literacy Confference). $19 \mathrm{f}$. Columbus, Ohio, sept.1988. Disponível em: <http://files.eric. ed.gov/fulltext/ED297304.pdf>. Acesso em: 31 jan. 2017.

FONSECA, Rui. The Development of Literacy Programmes in Mozambique. In: FORDHAM, Paul. One billion illiterates, one billion reasons for action (Report and extracts from papers of on International Seminar on cooperating for literacy). Berlim - West Germany, p.152157, oct. 1983. Disponível em: <https://archive.org/details/ ERIC_ED256930>. Acesso em: 31 jan. 2017.

GÓMEZ, Miguel Buendia. Educação Moçambicana: história de um processo (1962-1984). Maputo: Livraria Universitária (Universidade Eduardo Mondlane), 1999.

MÁRIO, Mouzinho; GÓMEZ, Miguel Buendia; KOUWENHOVEN, Wim; ALBERTO, Adalberto; WADDINGTON, Clotilde. Review of Education Sector Analysis in Mozambique, 1990-1998. Working Group on Education Sector Analysis. Paris: UNESCO, 2002. Disponível em: <http://unesdoc.unesco.org/ images/0012/001251/125122Eo.pdf>. Acesso em: 31 jan. 2017.

OLIVEIRA, Antônio de Almeida. O ensino público. Brasília: Senado Federal, 1873. Disponível em: $<\mathrm{http}: /$ livraria.senado.leg.br/o-ensino-publico.html>. Acesso em: 31 jan. 2017.

SUMICH, Jason. Construir uma nação: ideologias de modernidade da elite moçambicana. In: GRANJO, Paulo (Org.). Análise Social: Revista do Instituto de Ciências Sociais da Universidade de Lisboa. Lisboa: Universidade de Lisboa, 2008.

TEMPO. Educação, viver de alternativas. In: Revista Tempo, n. 909, Maputo, Moçambique, fev. 1988.

TEMPO. Escolas da Cidade de Maputo assinam compromissos de elevação de rendimento escolar. In: Revista Tempo, n. 756, Maputo, Moçambique, abr. 1985.

TEMPO. Orçamento chaga apenas para manter Aparelho de Ensino a funcionar. In: Revista Tempo, n. 979, Maputo, Moçambique, jul.1989.

TEMPO. Profissionais da Educação: ainda longe da meta apesar dos esforços. In: Revista Tempo, n. 800, Maputo, Moçambique, fev. 1986.

TEMPO. Resolução Geral da Conferência Extraordinária da Organização da Mulher Moçambicana. Revista Tempo, n. 737, Maputo, Moçambique, nov. 1984.

TEMPO. Revisão da Constituição da República de Moçambique. In: Revista Tempo, n. 1004, Maputo, Moçambique, jan. 1990.
TEMPO. SNE: último ano do I grau introduzido nas escolas primárias. In: Revista Tempo, n. 849, Maputo, Moçambique, jan. 1987.

Recebido em: 08.06.2017

Aceito em: 07.08.2017 